\title{
Simulated Annealing Optimization of PMBLDC Motor Speed and Current Controllers
}

\author{
MAAD SHATNAWI $^{{ }^{*}}$ and EHAB BAYOUMI ${ }^{2}$ \\ Department of Electrical Engineering Technology, Higher Colleges of Technology, Abu Dhabi, UAE \\ ${ }^{2}$ Department of Power Electronics and Energy conversion, Electronics Research Institute, Cairo, \\ EGYPT
}

\begin{abstract}
Brushless Direct-Current (BLDC) motors have several advantages including high efficiency and high speed ranges and accordingly are commonly used in a broad range of industrial applications. The optimization of the proportional-integral (PI) and proportional-integral-derivative (PID) controller parameters are highly explored and a number of tuning techniques have been proposed. This work demonstrates a permanent magnet brushless Direct-Current (PMBLDC) motor controller design method by employing a simulated annealing optimization (SAO) algorithm to optimize the current controller and speed controller parameters to concurrently minimize over-shoot, rise-time, and settling-time. We compared the proposed approach with the Particle Swarm Optimization and the Ziegler-Nichols approaches and showed that the proposed approach outperforms both of the other two approaches.
\end{abstract}

Key-Words: - Simulated annealing, controller optimization, BLDC motor.

Received: March 16, 2020. Revised: September 6, 2020. Accepted: September 18, 2020. Published: October 1, 2020.

\section{Introduction}

The Brushless Direct-Current (BLDC) motors are characterized by several characteristics including the high efficiency, wide speed ranges, and great power-toweight ratio, and therefore, they are commonly used in numerous domains such as aerospace, automotive, medical, automation and instrumentation equipment [19]. The proportional-integral (PI) and proportionalintegral-derivative (PID) controllers are intensely studied in various research papers. These controllers started their attractiveness after the development of the classic Ziegler-Nichols (ZN) technique [10].

There are a variety of tuning approaches proposed to adapt the exceptional requirement of contemporary industry optimization to the PID parameters such as [11-17]. However, evolutionary computations with stochastic search techniques have showed more capability to solve controller parameters estimation problem. The evolutionary computation approaches have been employed to optimize BLDC motor drive system parameters. Examples of these approaches are Genetic algorithm (GA) [18], Particle Swarm Optimization (PSO) [19-21], Bacterial Foraging Optimization (BFO) [22]. However, these evolutionary approaches suffer from high computational complexity $[21,23]$.

This paper introduces an effective design approach for a permanent magnet brushless Direct-Current (PMBLDC) motor drive current and speed controllers where a Simulated Annealing Optimization (SAO) algorithm is developed to tune the parameters of PID/PI controllers. The maximum over-shoot, rise-time and settling-time are all simultaneously minimized within the tuning process. The proposed algorithm is tested and compared with both PSO and ZN techniques.

This paper is organized as follows. Section 2 introduces the overall block diagram of PMBLDC motor drive system. Section 3 presents the PI/PID controllers optimization for over-shoot, rise-time, and settling minimization through SAO. The results of the proposed approach are presented in Section 4. Section 5 provides some conclusion remarks on the proposed approach for controlling PMBLDC motor drive system.

\section{PMBLDC Motor Drive System}

The PMBLDC motor drive system given in Fig. 1, is consisting of two-cascade control loop. The inner loop is the current control loop and the outer loop is the speed control loop. In the inner loop, PI regulator is employed while a PID regulator is used to control the speed in the outer control loop. The main issue in this paper is how to optimize the two controller parameters to guaranteed fast and superior responses. To do so, the Simulating Annealing Optimization (SAO) technique which will be discussed and explained in the next section has been selected for this purpose.

The system parameters [20, 24, 25] are:

$R_{s}$ is the per-phase stator resistance, $L_{s}$ is the per-phase stator inductance, $e$ is the per-phase stator voltage, $\omega_{m}$ is the rotor speed 
$v_{s}$ is the phase stator voltage,

$i_{s}$ is the stator current,

$T_{e}$ is the electromagnetic torque,

$T_{L}$ is the load torque,

$K_{T}$ is the load torque constant,

$K_{b}$ is the flux constant (volt $\left./ \mathrm{rad} / \mathrm{sec}\right)$,

$B$ is the motor friction, and

$J$ is the motor moment of inertia.

Many applications gain by the engagement of BLDC motors. Due to the slight size of this motor typology, it can be used in applications that require accurate control movements within narrow places such as medical applications. The Electric Vehicles (EV) industry is observing with excessive attention to the engagement of BLDC motors in their systems. Due to their optimum structures and high efficiency, BLDC motors are promising candidates to be engaged in this domain.

\section{Simulated Annealing Optimization}

Simulated Annealing [26] is an efficient iterative single-objective and multi-objective optimization approach inspired by the thermal annealing method where a cooling parameter $T$ is decreased during its iterations according to a decade factor $\alpha[27,28]$. One important feature of the Simulated Annealing Optimization (SAO) approach is its ability to avoid being trapped in local-minima by accepting some changes that momentarily degrade its objective or fitness function $f(S)$ of state $S[29,30]$. SAO guarantees to converge to the global-minima if the cooling is slowly performed [31-34]. SAO have been applied to numerous engineering and real life applications and achieved promising results [28, 33, 35-44].

We employed SAO to find the optimal current and speed controller parameters $\left(K_{p}, T_{i}\right.$, and $\left.T_{D}\right)$ that simultaneously minimizes three fitness functions which are over-shoot, rise-time and settling-time of the control index. As illustrated in Fig. 2, $K_{p}, T_{i}$, and $T_{D}$ are arbitrarily initialised and, during the optimization process, SAO makes a transition in the search space by randomly applying a small increment or decrement to the controller parameters and it then finds the new fitness functions. SAO accepts this transition if it leads to a decrease in all fitness functions or a decrease in one of them if other fitness functions are not affected. SAO also randomly accepts any other transition with a probability of $e^{-\Delta f / T}$, where $\Delta f=f\left(S_{2}\right)-f\left(S_{1}\right)$. The iterative process will continue until convergence or reaching a pre-defined maximum number of iterations.

\section{PMBLDC Motor Controller Optimization}

The parameters of the PMBLDC motor drive, converter and transducers are in [25]. The current controller of PMBLDC motor drive model is presented in Fig. 3. The complexity of the model can be reduced ending up with the open loop transfer function as:

$$
G_{\text {current_openloop }}=\frac{k_{p} K_{r} K_{c}\left(1+T_{i} s\right)}{T_{i} s\left(1+T_{r} s\right)\left(R_{a}+L_{a} s\right)\left(1+T_{c} s\right)}
$$

where,

$K_{r}$ is the inverter gain,

$T_{r}$ is the time constant of the inverter,

$K_{c}$ is the current transducer gain, and

$T_{c}$ is the current transducer time constant.

The transfer function of the PI current controller is:

$$
G_{c}(s)=\frac{k_{p} T_{i} s+k_{p}}{T_{i} s}
$$

SAO is employed to find $k_{p}$ and $T_{i}$ parameter values that simultaneously minimize over-shoot, rise-time, and settling-time as illustrated in Fig. 4. SAO achieves the optimal values for $k_{p}$ and $T_{i}$ of 0.932 and 0.001765 respectively and therefore the resulting PI controller is:

$$
G_{P I}(s)=\frac{0.001645 s+0.932}{0.001765 s}
$$

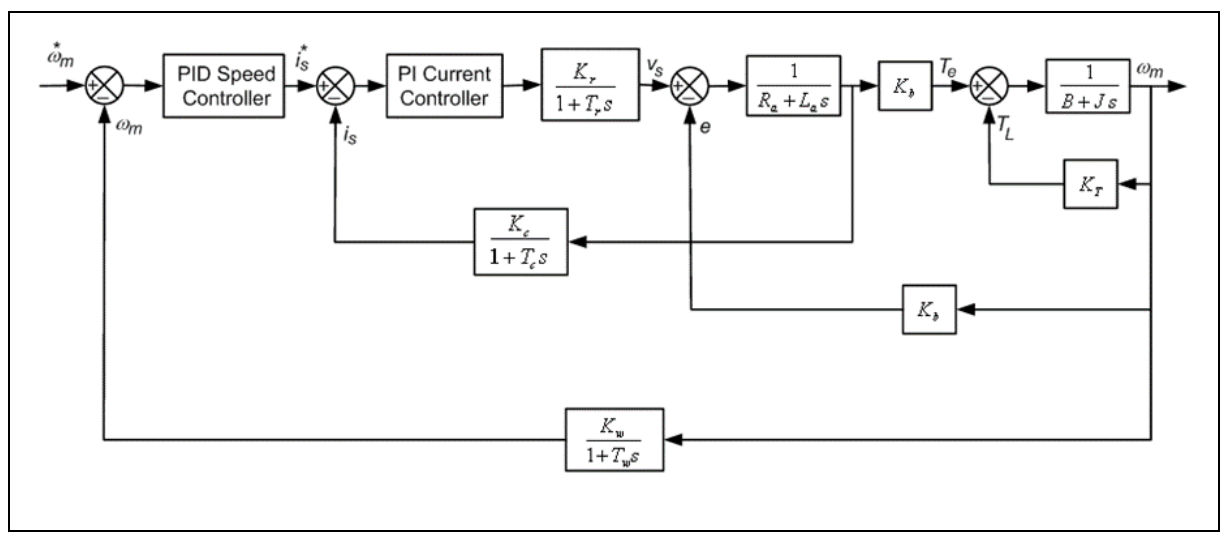

Fig. 1 The PMBLDC motor drive system contrller. 


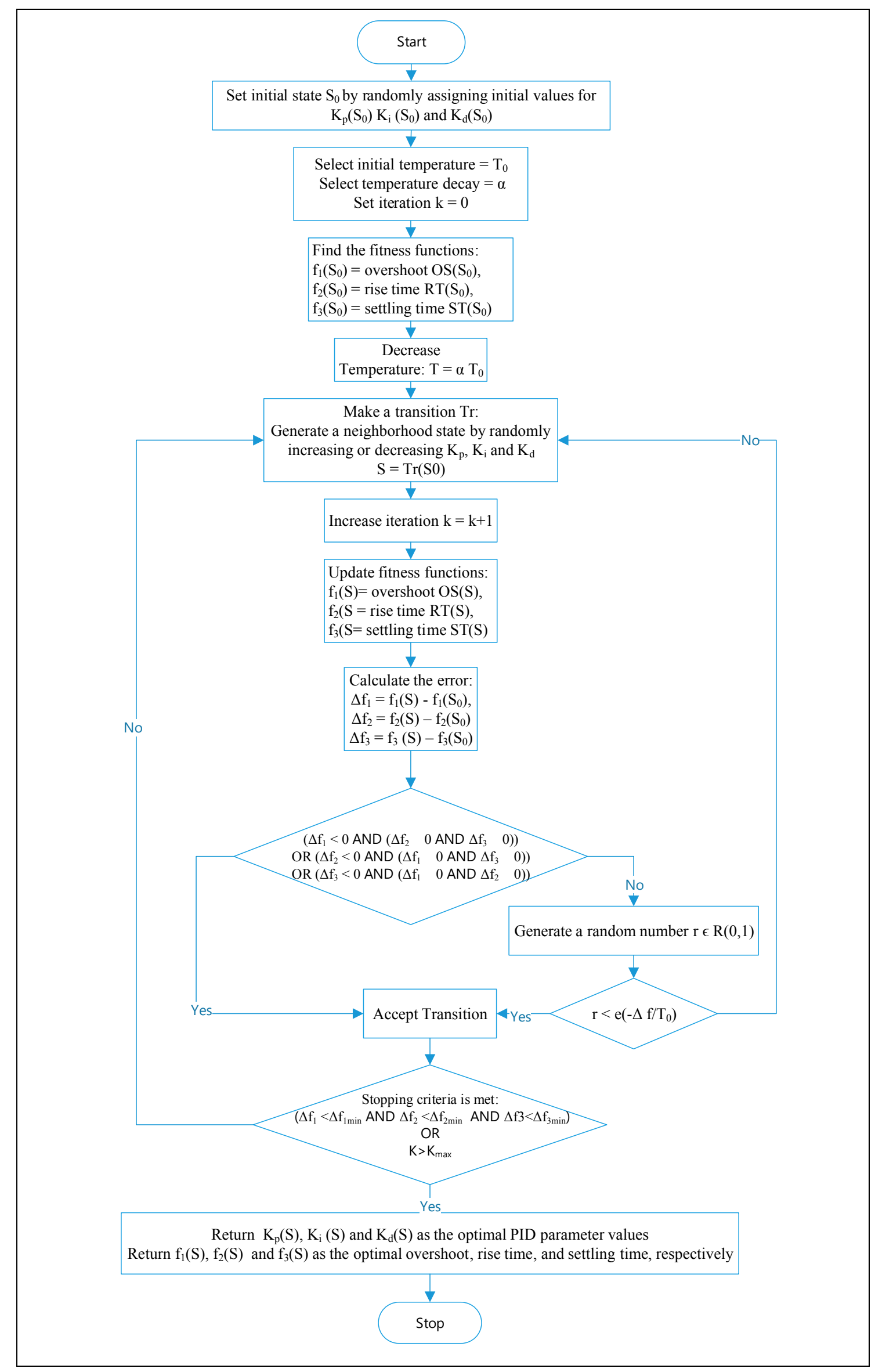

Fig. 2 SAO for motor controller optimization. 


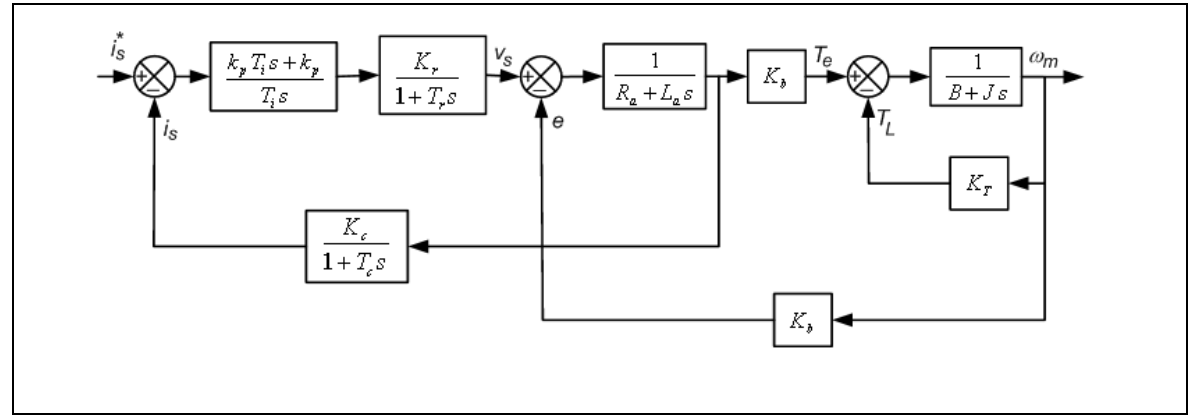

Fig. 3 Current control loop for the motor drive system.

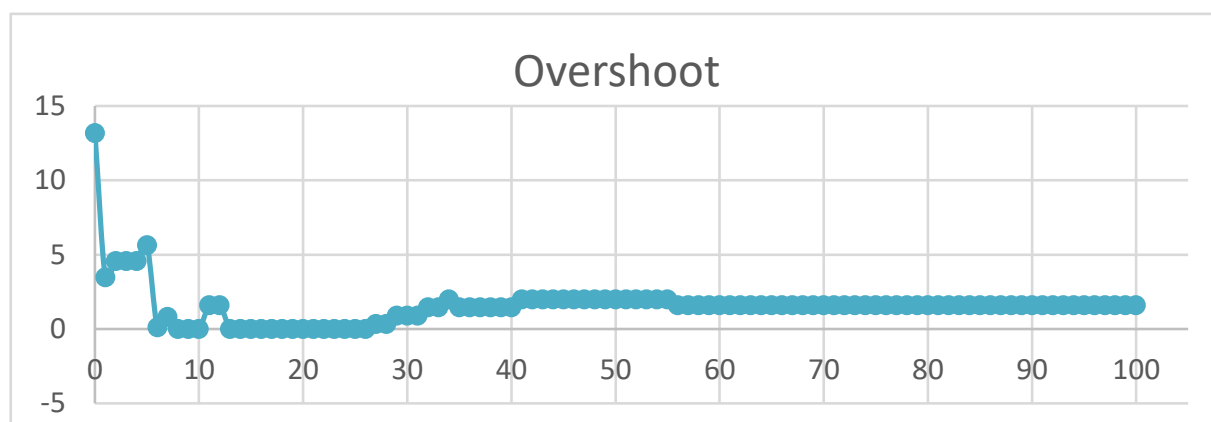

(A) Maximum percent over-shoot vs. iterations.

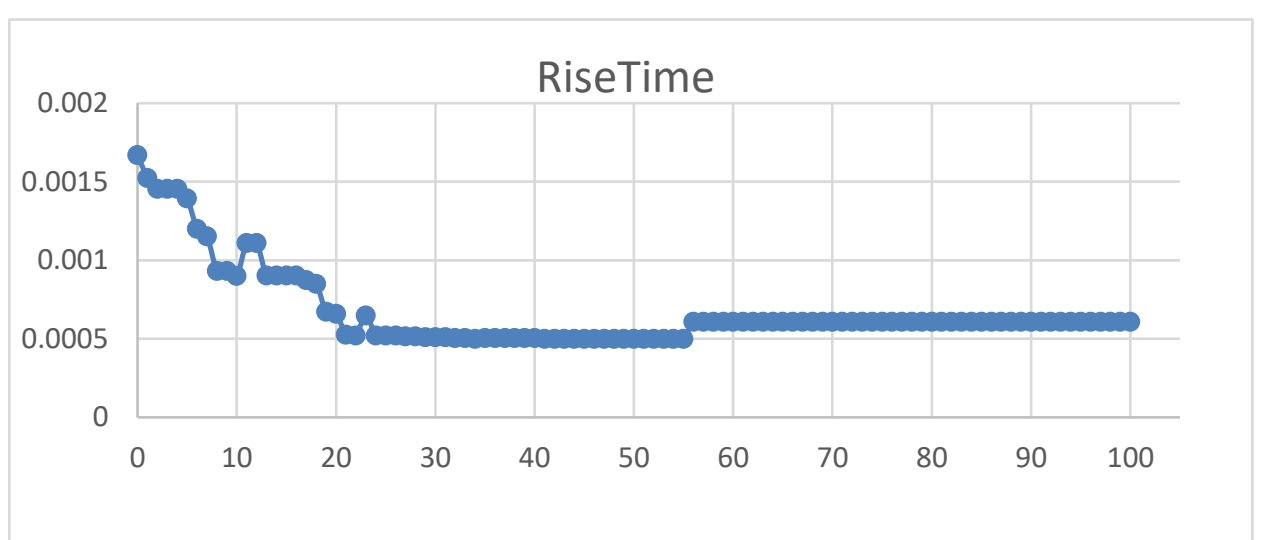

(B) Rise-time vs. iterations.

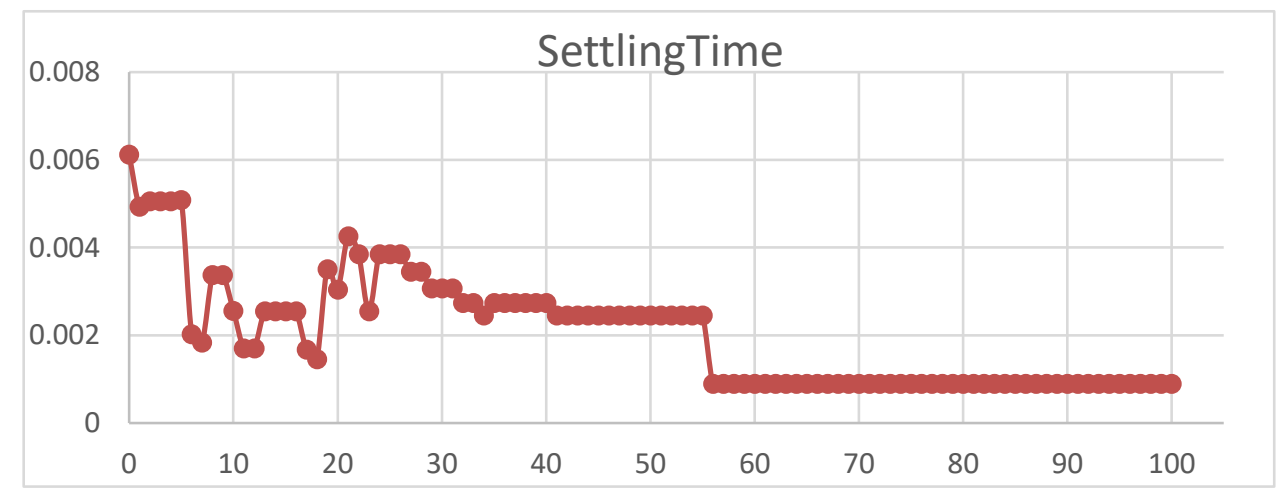

(C) Settling-time vs. iterations.

Fig. 4 Maximum percent over-shoot, rise-time and settling-time trends for the PI current controller during the optimization process. 


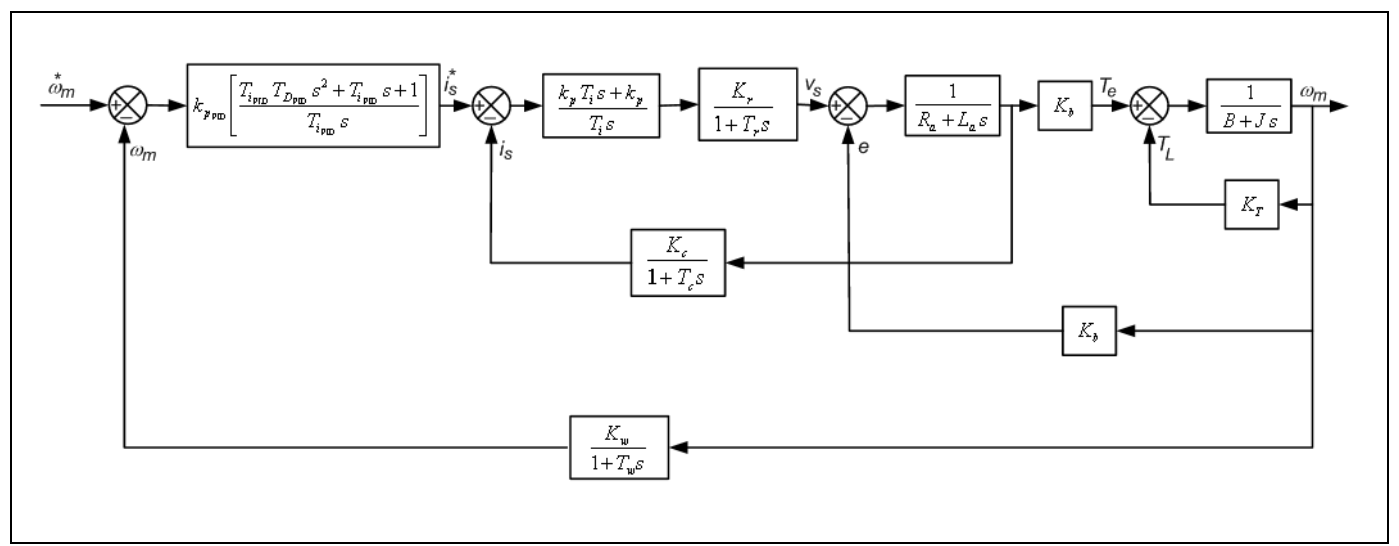

Fig. 5 Speed control loop for the motor drive system.

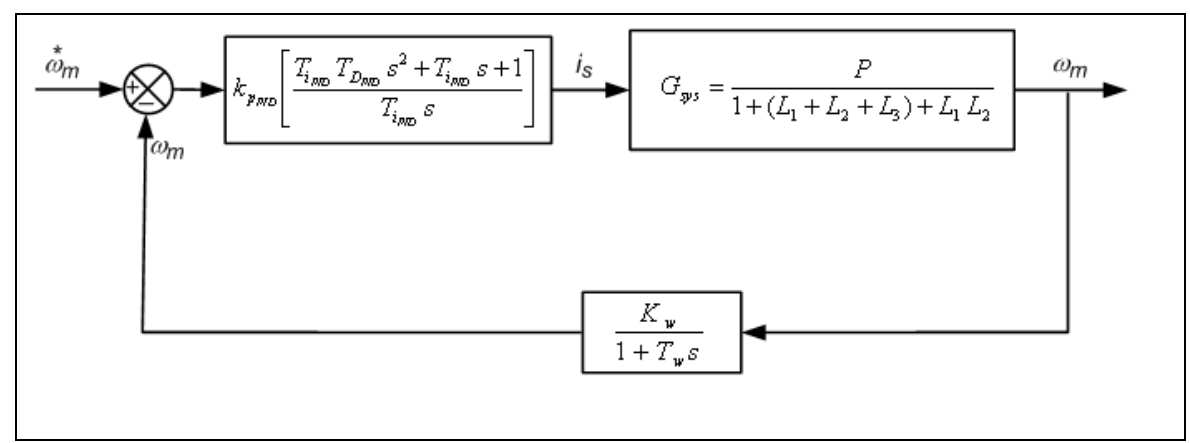

Fig. 6 Reduced block diagram of the speed control loop for the motor drive system.

The speed controller of PMBLDC motor drive model is presented in Fig. 5. The complexity of the model can be reduced using Mason's rule as in Fig. 6 ending up with the open loop transfer function as:

$$
G_{s y s}=\frac{\omega_{m}(s)}{I^{*}{ }^{*}(s)}=\frac{P}{1+\left(L_{1}+L_{2}+L_{3}\right)+L_{1} L_{2}}
$$

where the gains of the forward loops are:

$$
\begin{gathered}
P=\frac{k_{p} K_{r} K_{b}\left(1+T_{i} s\right)}{T_{i} s\left(1+T_{r} s\right)\left(R_{a}+L_{a} s\right)(B+J s)} \\
L_{1}=-\frac{k_{p} K_{r} K_{c}\left(1+T_{i} s\right)}{T_{i} s\left(1+T_{r} s\right)\left(R_{a}+L_{a} s\right)\left(1+T_{c} s\right)} \\
L_{2}=-\frac{K_{T}}{(B+J s)} \\
L_{3}=-\frac{K_{b}^{2}}{\left(R_{a}+L_{a} s\right)(B+J s)}
\end{gathered}
$$

The open loop transfer function of the speed controller is:

$$
G_{\text {speed_openloop }}=\frac{k_{p_{P I D}} P K_{w}\left(T_{i_{P I D}} T_{D_{P I D}} s^{2}+T_{i_{P I D}} s+1\right)}{T_{i_{P I D}} s\left(1+\left(L_{1}+L_{2}+L_{3}\right)+L_{1} L_{2}\right)\left(1+T_{w} s\right)}(9)
$$

where,

$\mathrm{K}_{\mathrm{w}}$ is the speed transducer gain,

$\mathrm{T}_{\mathrm{w}}$ is the speed transducer time constant, and $k_{p_{P I D}}, T_{i_{P I D}}, T_{D_{P I D}}$ are the PID controller parameters. The PID speed controller transfer function is:

$$
G_{s}(s)=k_{p} \frac{T_{i} T_{d} s^{2}+T_{i} s+1}{T_{i} s}
$$

SAO is employed to find the values of $k_{p}, T_{i}$ and $T_{d}$ that simultaneously minimize over-shoot, rise-time, and settling-time as illustrated in Fig. 7. SAO achieves the optimal values for $k_{p}, T_{i}$ and $T_{d}$ of 14.6265, 0.0448 and 0.0000102553 respectively and therefore the resulting PID controller is:

$$
G_{P I D}(s)=14.6265 \frac{\left(4.596 \times 10^{-7} s^{2}+0.0448 s+1\right)}{0.0448 s}
$$




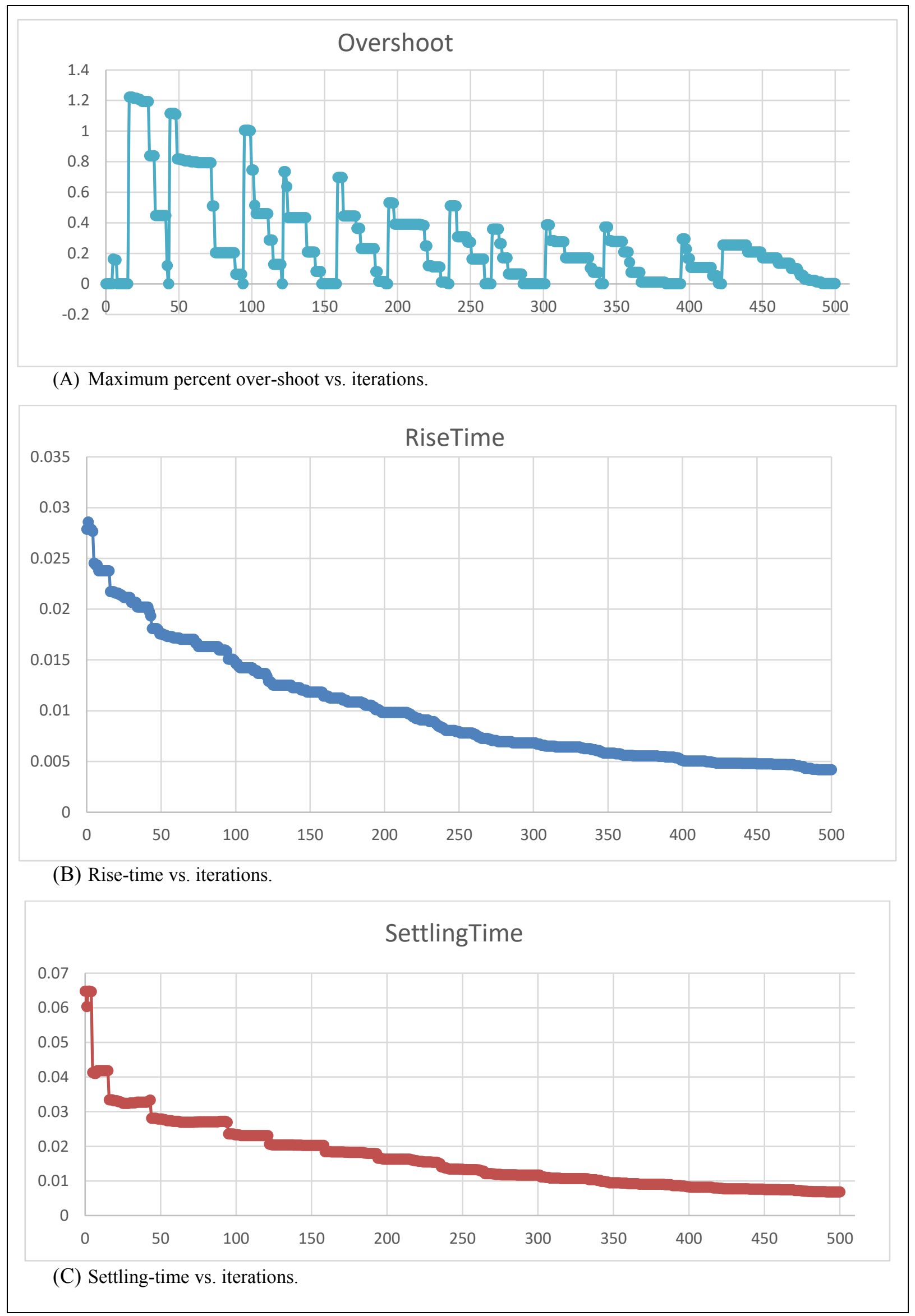

Fig. 7 Maximum percent over-shoot, rise-time and settling-time trends for the PID speed controller during the optimization process. 


\section{Results}

The proposed PI current controller is examined at heavy, nominal, and light loading circumstances which are modelled as $150 \%, 100 \%$ and $50 \%$ of the rated value of $R_{a}$ as shown in Fig. 8. It is illustrated that, the maximum over-shoot doesn't exceed $7.8 \%$ in its poorest case. We compared our suggested PI controller with PSO and ZN controllers. The ZN current controller [11] is:

$$
G_{P I_{-} Z N}=\frac{0.003623 s+6.67}{5.44 \times 10^{-4} s}
$$

where $K_{p}=6.67, T_{i}=5.44 \times 10^{-4}, K_{i}=12261$. The PSO current controller [20] is:

$$
G_{P I_{-} P S O}(s)=\frac{0.01063 s+1.9816}{0.0054 s}
$$

where $K_{p}=1.9816, T_{i}=0.0054, K_{i}=24.04 \times 10^{6}$. We compared the three controllers at 50\%, 75\%, 100\%, and $150 \%$ of $R_{a}$. Fig. 9 clearly illustrates the outperformance of the proposed controller over the other two controllers which point out that the motor can run safer and more secure through transitory situations.

To assess the efficacy of the proposed PID speed controller, it was examined at three armature resistance values $\left(50 \%, 100 \%\right.$ and $150 \%$ of $\left.R_{a}\right)$ as illustrated in Fig. 10 and at three moment of inertia values $(50 \%$, $100 \%$ and $150 \%$ of $J$ ) as illustrated in Fig. 11 . We then compared our proposed PID controller with PSO and $\mathrm{ZN}$ controllers. The ZN speed controller [11] is:

$G_{P I D_{Z} Z N}(s)=208.8 \frac{\left(5.0625 \times 10^{-8} s^{2}+4.5 \times 10^{-4} s+1\right)}{4.5 \times 10^{-4} s}$ where $K_{p}=208.8, T_{i}=5.44 \times 10^{-4}, K_{i}=464000, T_{d}$ $=1.125 \times 10^{-4}, K_{d}=0.02349$. The PSO speed controller [20] is:

$$
G_{P I D_{-} P S O}(s)=4.623 \frac{\left(0.013827 s^{2}+0.0569 s+1\right)}{0.0569 s}
$$

Fig. 12 demonstrates the profile of these controllers at the rated values of armature resistance and moment of intertie where it demonstrates the superiority the proposed SAO PID controller over the other two PID controllers in running the motor with a speed response with no over-shoot and lowest rise-time and settlingtime. The three PID controllers are then compared at $50 \%$ and $150 \%$ of the rated armature resistance. Fig. 13 illustrate the behaviour of the three controllers at $50 \%$ of $R_{a}$ while Fig. 14 illustrate their behaviour at $150 \%$ of $R_{a}$. The three PID controllers are then evaluated at $50 \%$ and $150 \%$ of the rated J parameter. Fig. 15 illustrate the behaviour of these controllers at $50 \%$ of J while Fig. 16 illustrate their behaviour at $150 \%$ of $\mathrm{J}$.

\section{Conclusion}

This work proposes a simple yet effective approach for current and speed controller optimization for permanent magnet brushless de motor drive system by simultaneously minimalizing over-shoot, rise-time and settling-time. We employed the Simulated Annealing Optimization technique. The proposed approach was tested on several motor loading situations and against Particle Swarm Optimization and Ziegler-Nichols approaches. The results indicated that the proposed SAO approach performs very well over the different loading conditions outperforming both Particle Swarm Optimization and Ziegler-Nichols approaches. As a future direction, this optimized BLDC motor typology can be examined in several precise control applications and in electric vehicles where high motor efficiency is required.

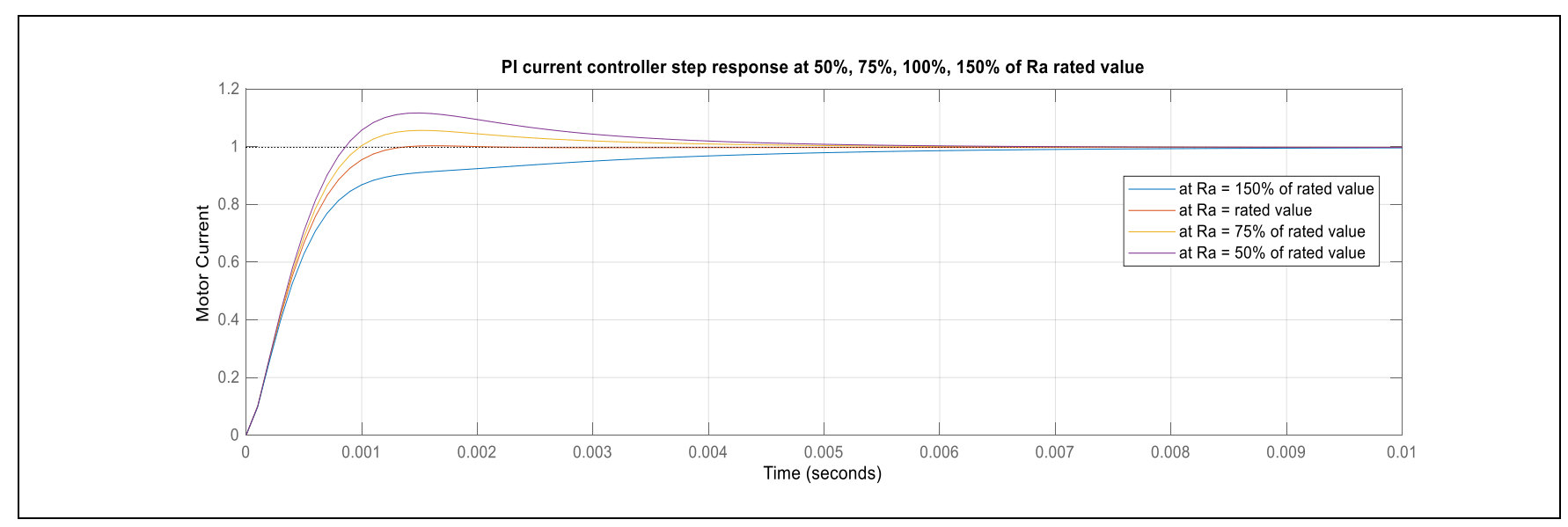

Fig. 8 The proposed current controller responses at various values of armature resistance. 


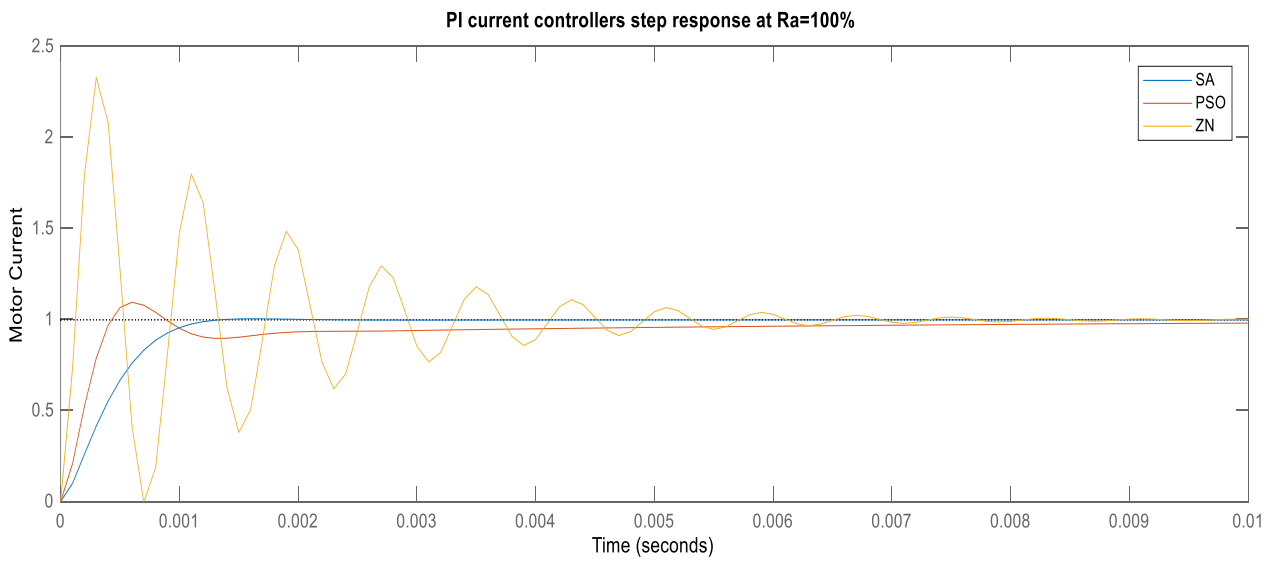

(A) at $\mathrm{R}_{\mathrm{a}}=100 \%$.

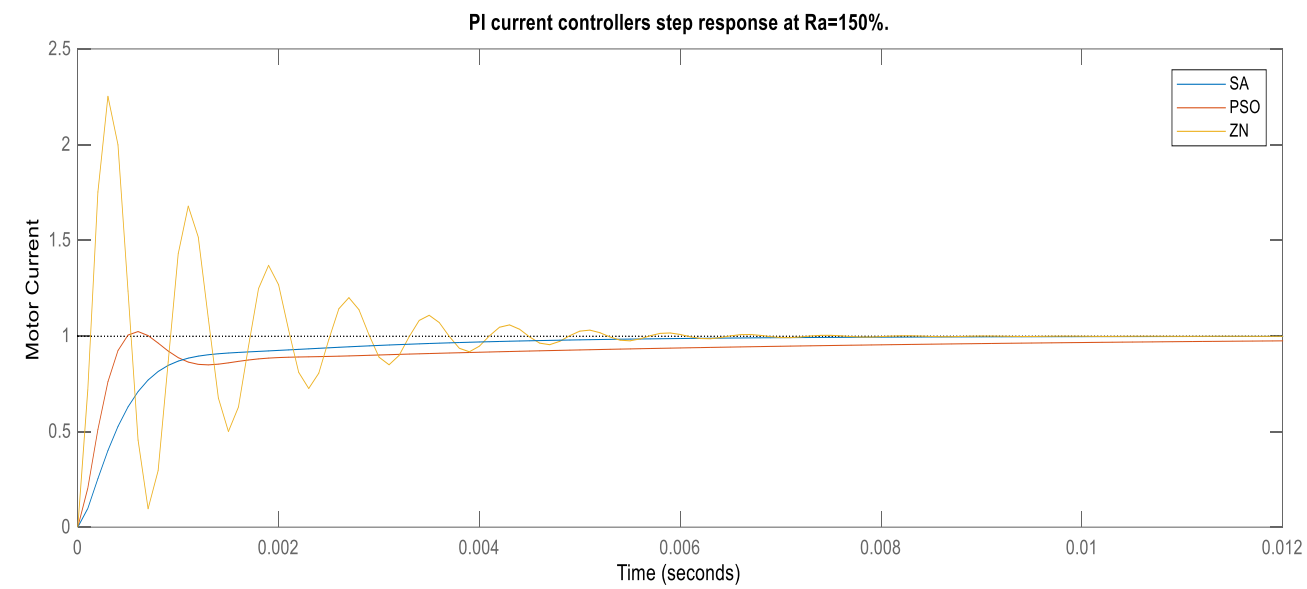

(B) at $\mathrm{R}_{\mathrm{a}}=150 \%$.

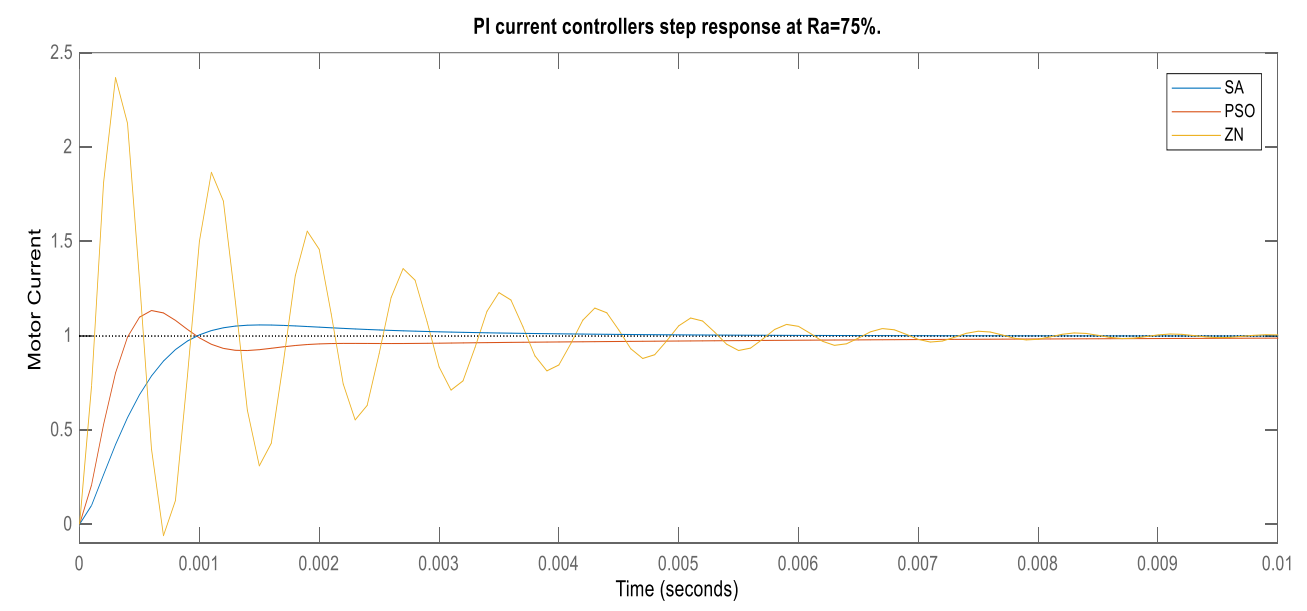

(C) at $\mathrm{R}_{\mathrm{a}}=75 \%$. 


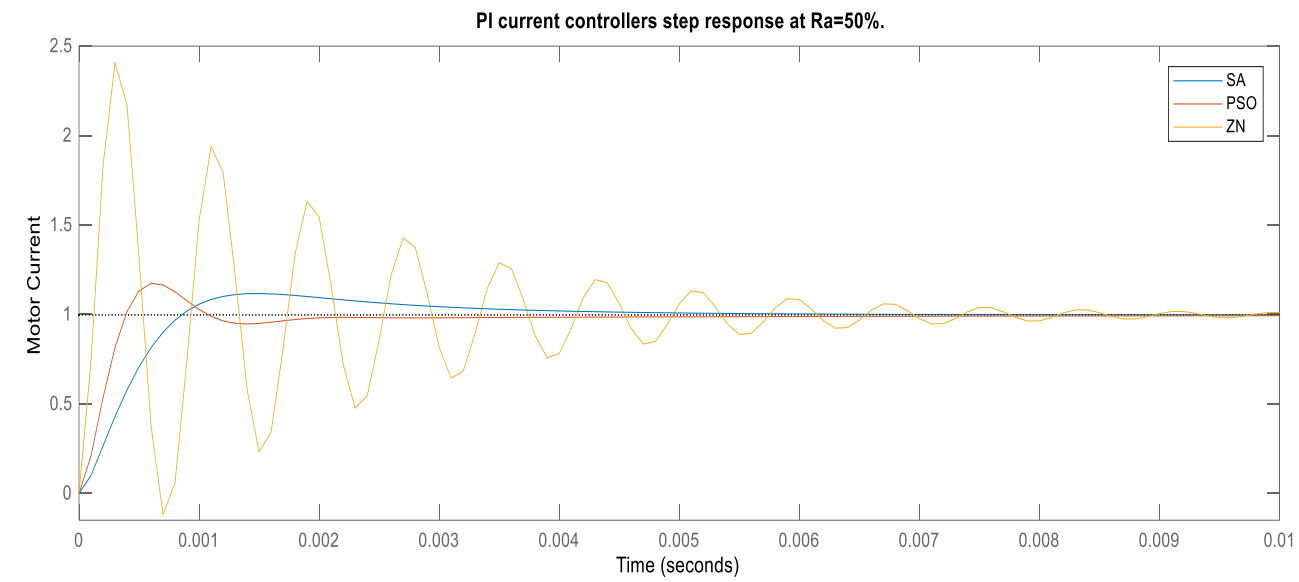

(D) at $\mathrm{R}_{\mathrm{a}}=50 \%$.

Fig. 9 Comparison of current controllers' responses at various values of armature resistance.

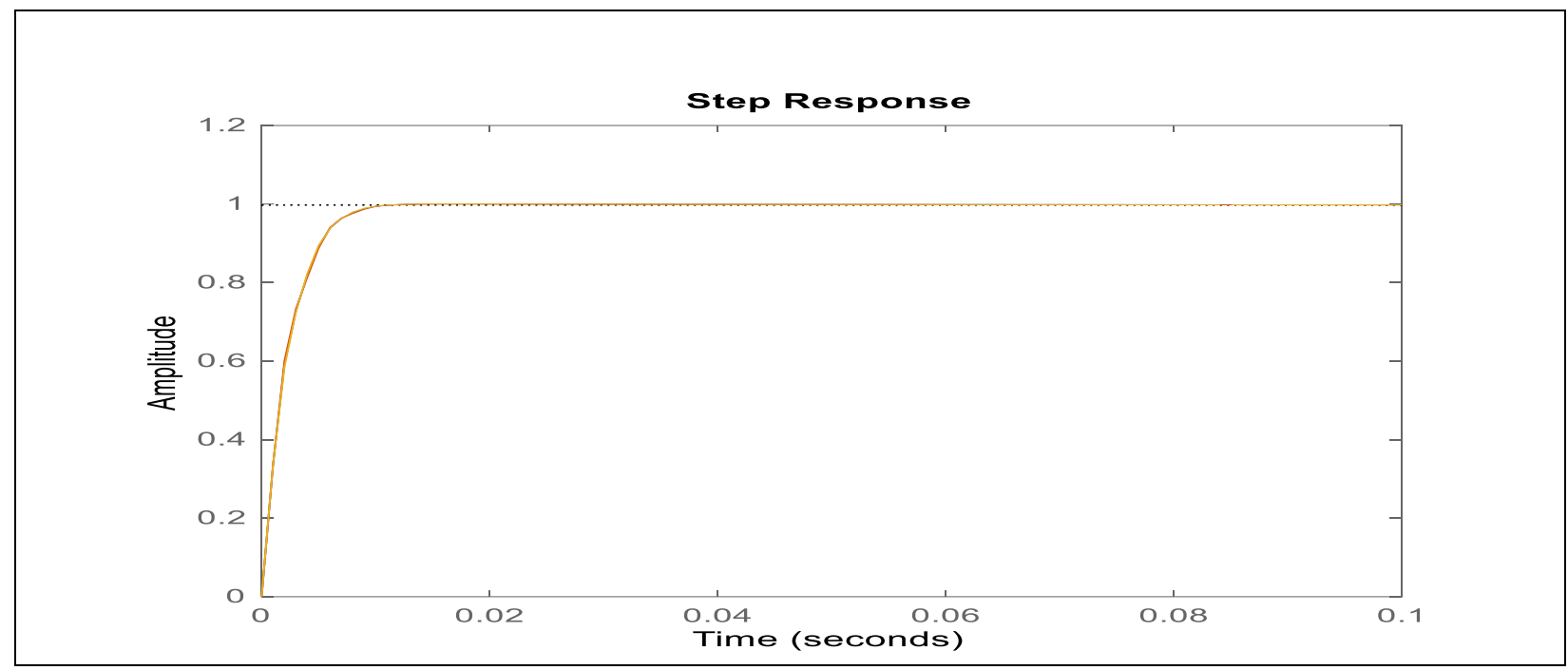

Fig. 10 The proposed speed controller responce.

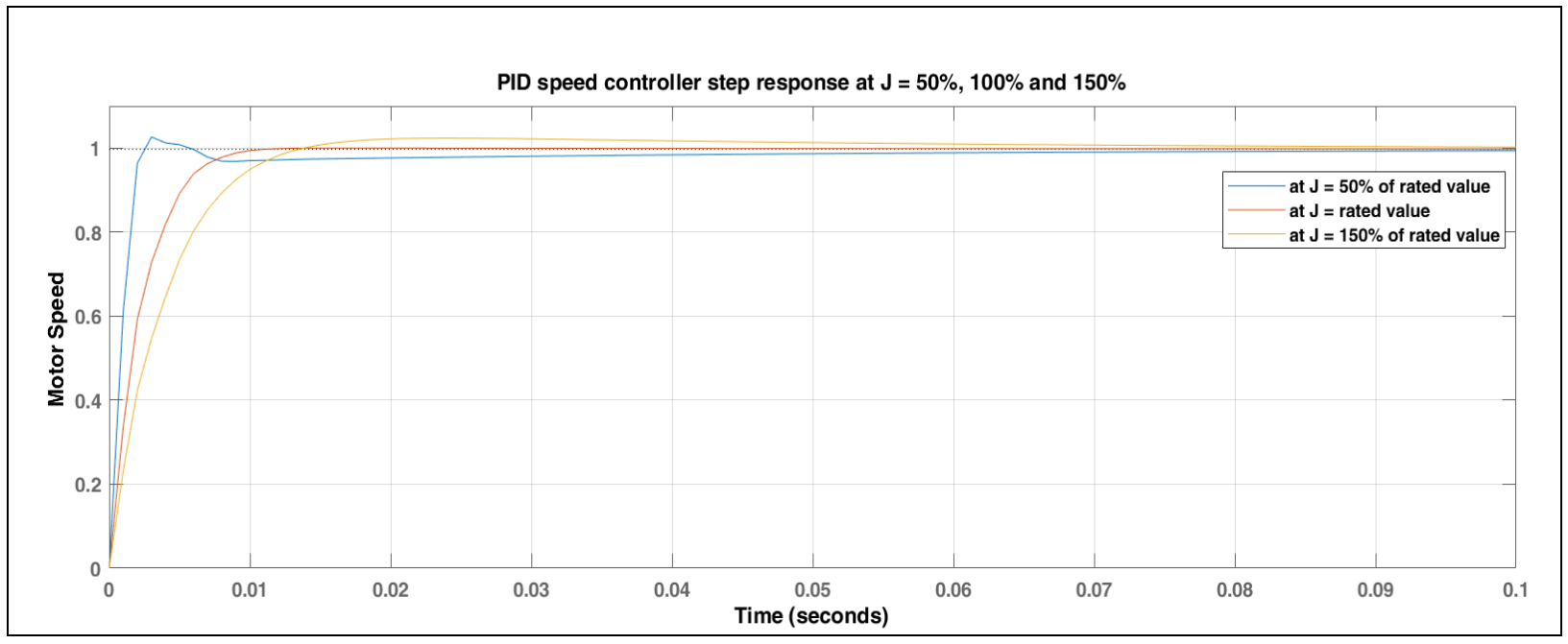

Fig. 11 The proposed speed controller response at different moment of inertia values. 


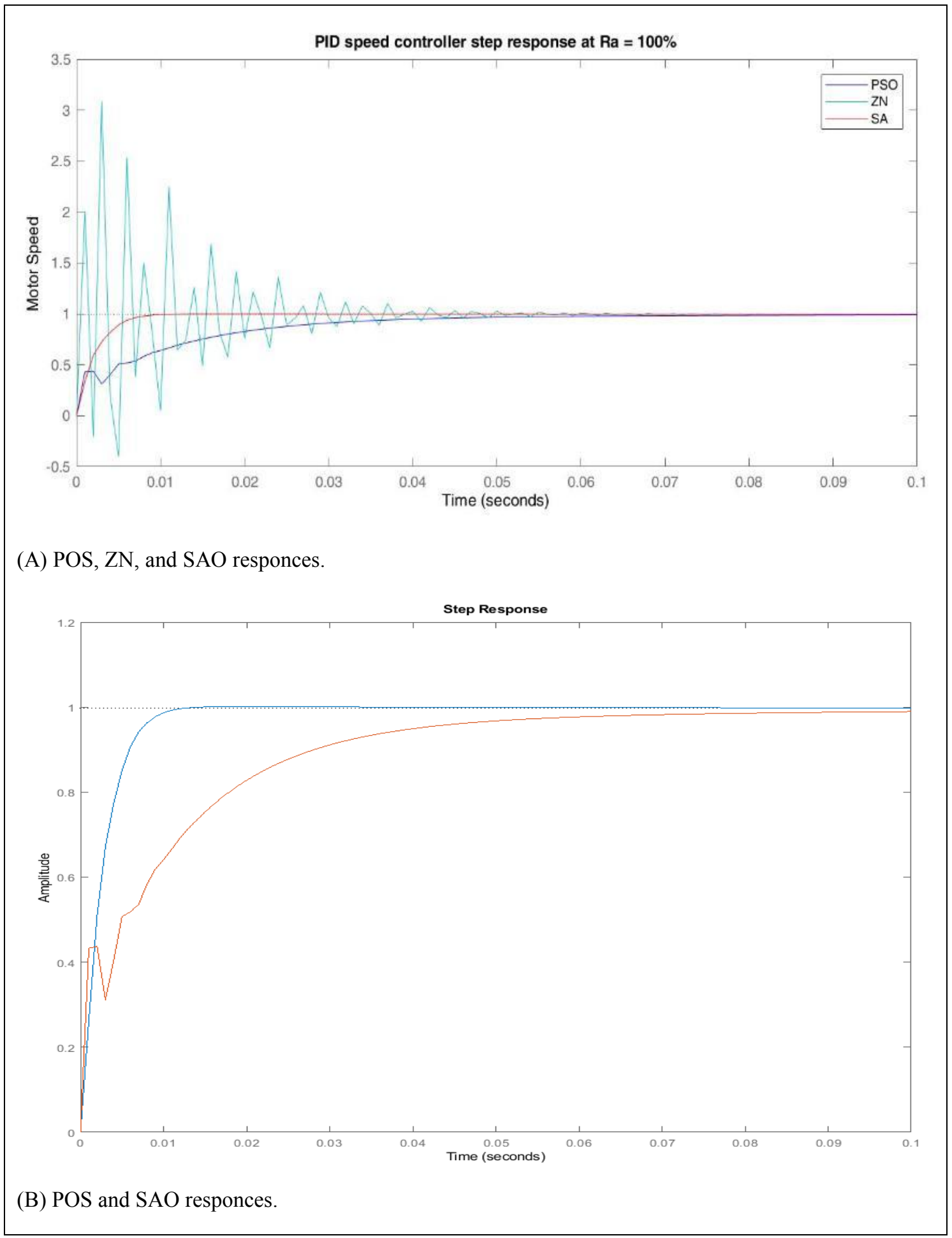

Fig. 12 POS, ZN, and SAO speed controllers' responses at $\mathrm{Ra}=100 \%$ and $\mathrm{J}=100 \%$. 


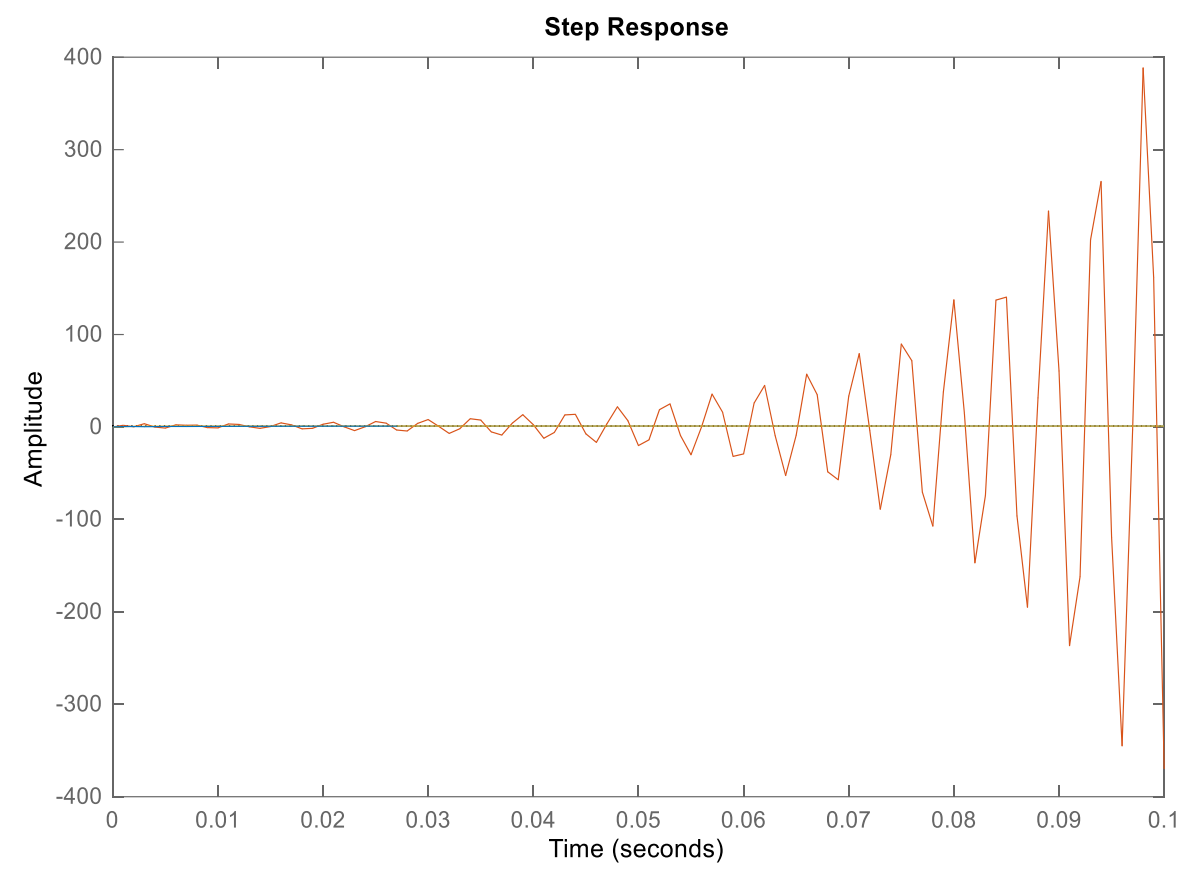

(A) POS, ZN, and SAO.

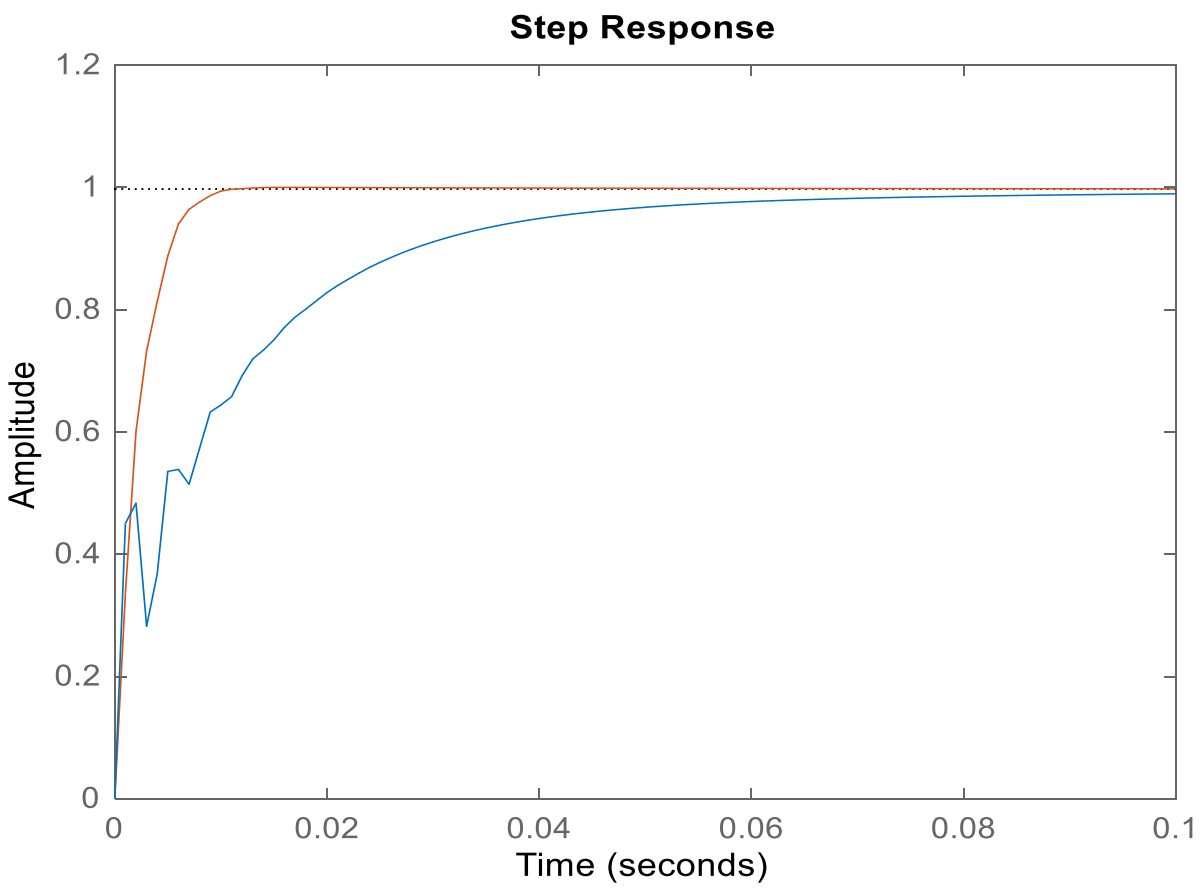

(B) POS and SAO.

Fig. 13 Comparison of the speed controllers' indices of POS, ZN, and $\mathrm{SAO}$ at $\mathrm{Ra}=150 \%$ and $\mathrm{J}=100 \%$. 


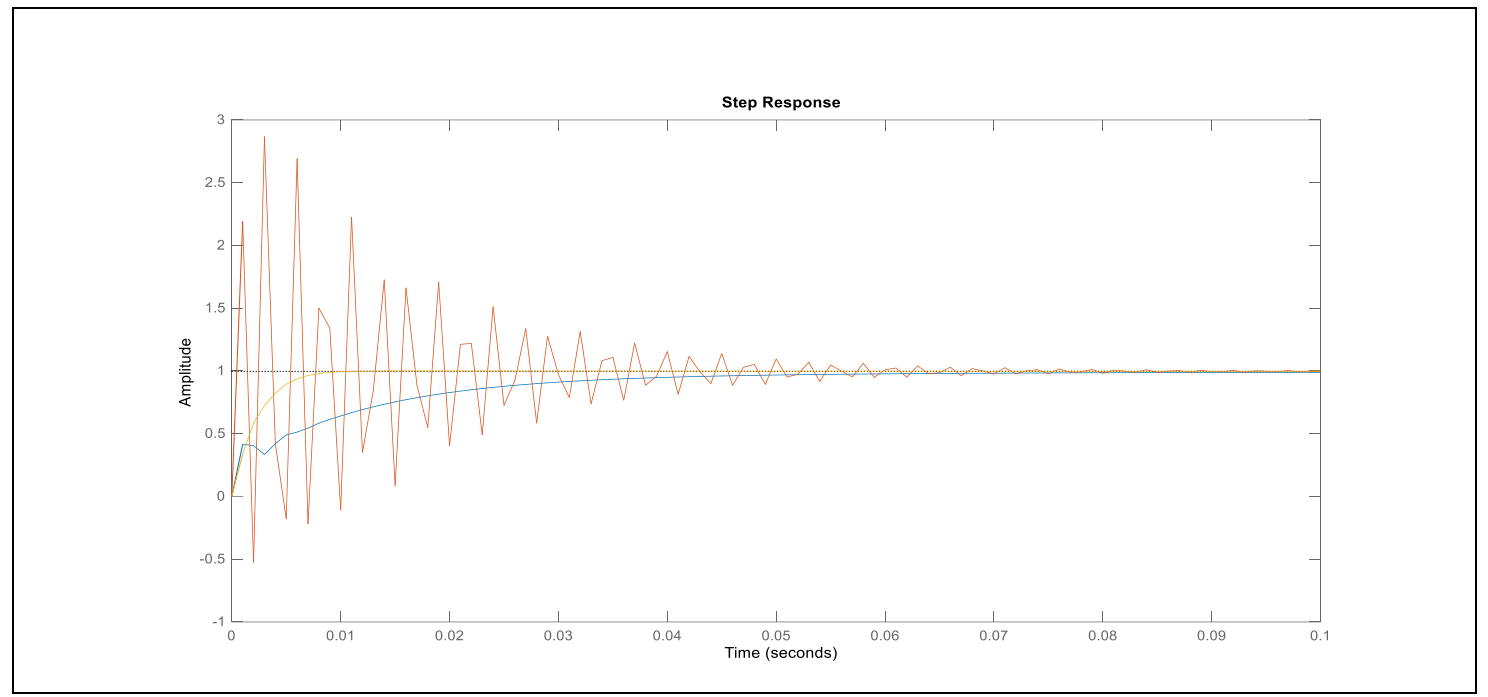

Fig. 14 Comparizon of the speed controllers' indices at $\mathrm{Ra}=150 \%$ and $\mathrm{J}=100 \%$.

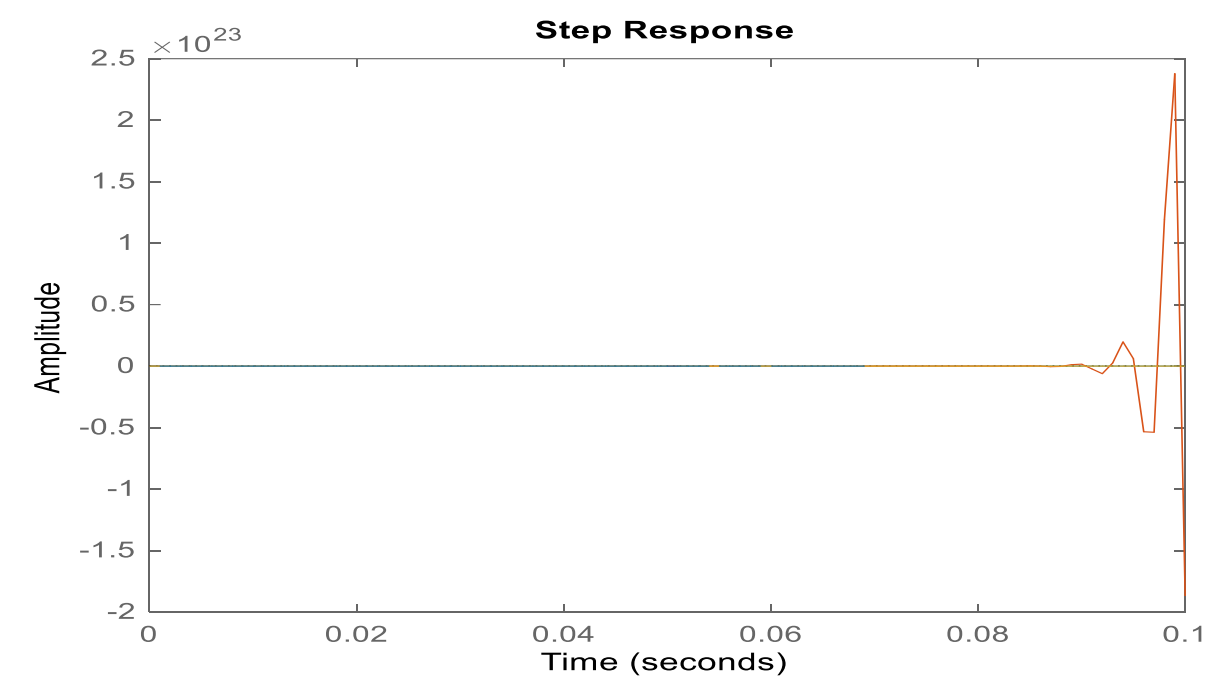

(A) POS, ZN, and SAO.

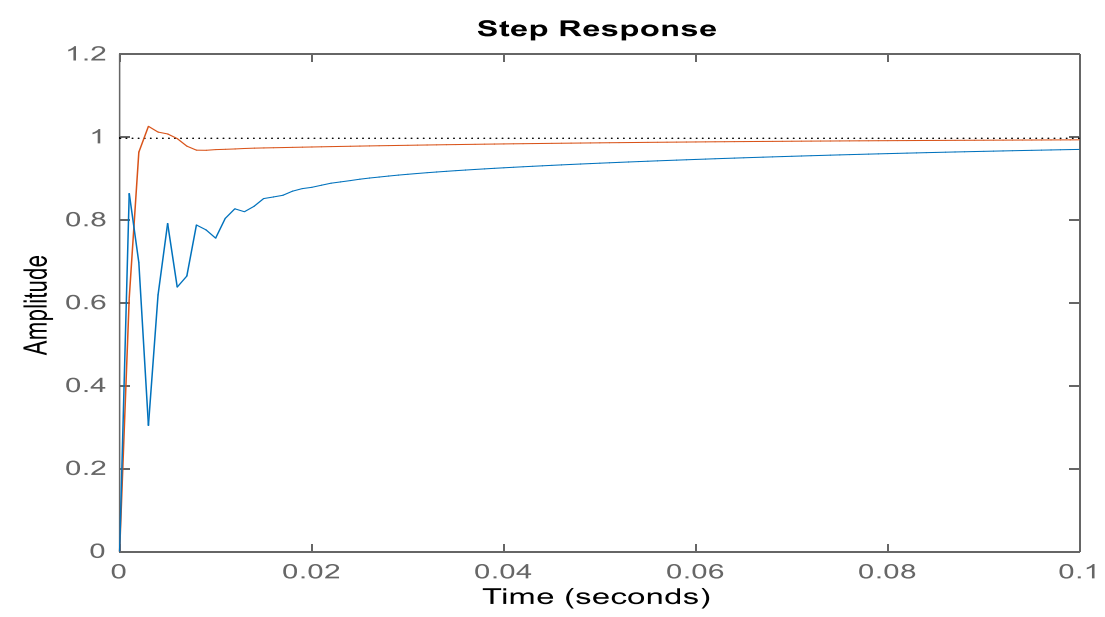

(B) POS and SAO.

Fig. 15 Comparizon of the speed controllers' indices at at $\mathrm{Ra}=100 \%$ and $\mathrm{J}=50 \%$. 


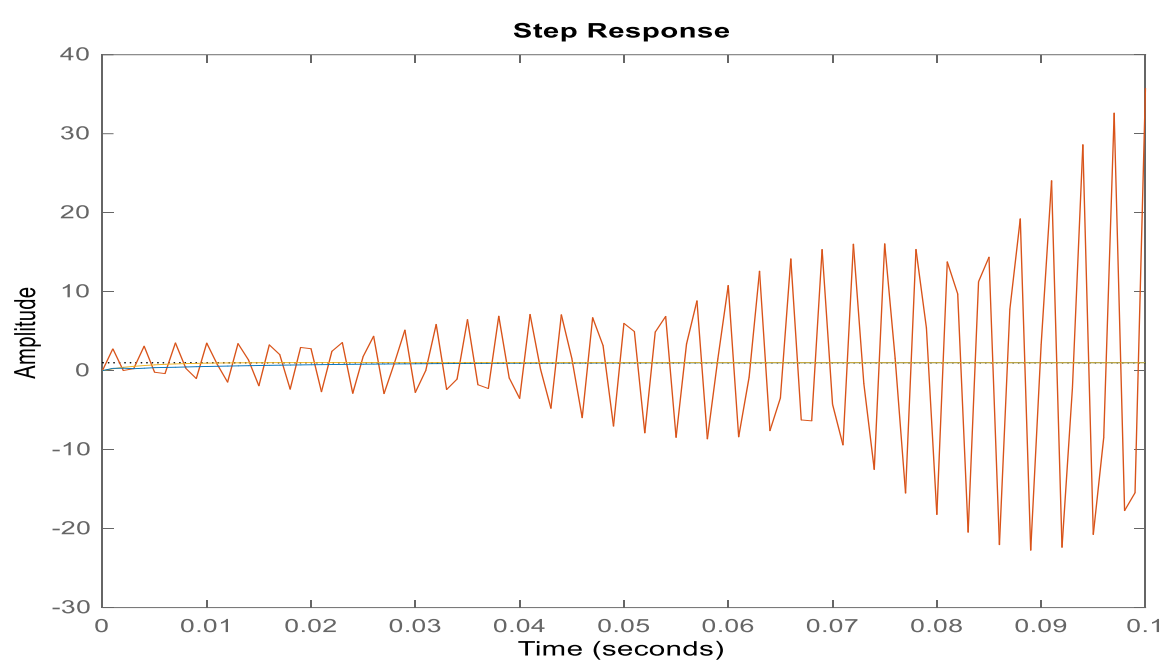

(A) POS, ZN, and SAO.

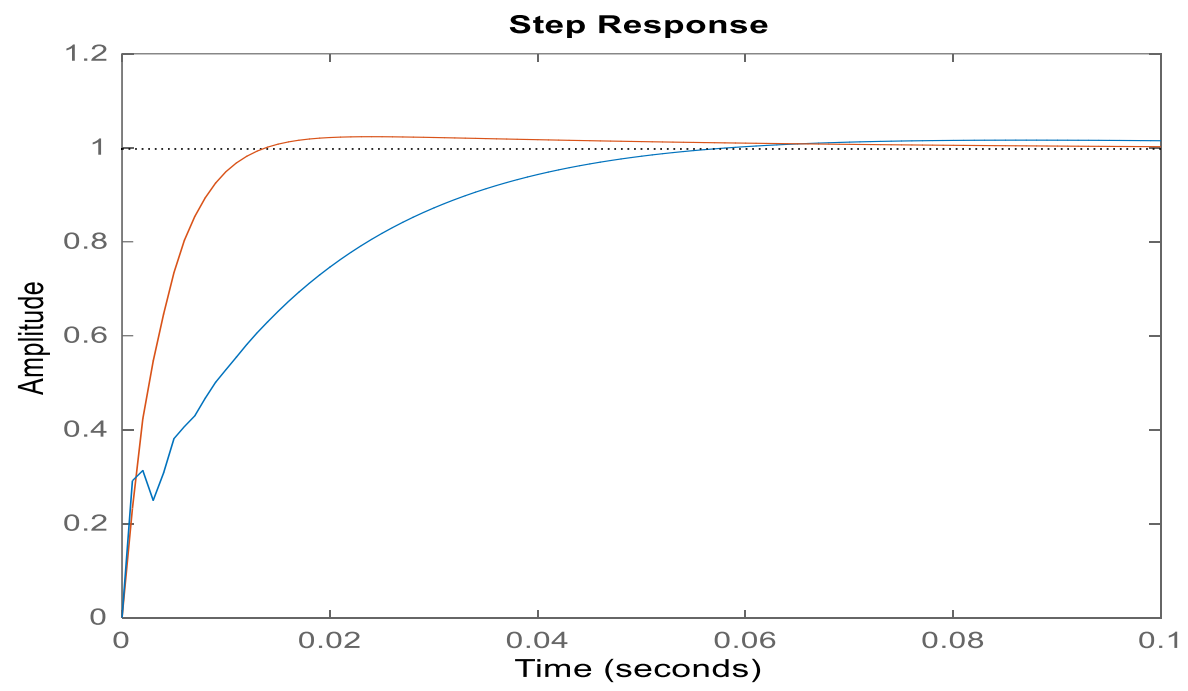

(B) POS and SAO.

Fig. 16 Comparison of the speed controllers' indices at $\mathrm{Ra}=100 \%$ and $\mathrm{J}=150 \%$.

References:

[1] Chan, C. C. and Chau, K. T. "An Overview of Power Electronics in Electric Vehicles", IEEE Trans. on Ind. Electron., vol. 44, no.1, pp. 3-13, Feb. 1997.

[2] L. Ben-Brahim, L. and A. Kawamura, "A Fully Digitized Field-Oriented Controlled Induction Motor Drive Using Only Current Sensors", IEEE Trans. on Ind. Electron., vol. 39, no. 3, pp. 241249, June 1992.
[3] Xue, Y., Xu, X., Habetler, T. G. and Divan, D. M. "A Stator Flux-Oriented Voltage Source VariableSpeed Based on DC Link Measurement," IEEE Trans. on Ind. Applicat., vol. 27, no.5, pp. 962-069, Sept/Oct. 1991.

[4] Bayoumi, E.H.E. "An improved approach of position and speed sensorless control for permanent magnet synchronous motor," Electromotion Scientofic Journal, vol.14, pp. 8190, 2007.

[5] Millner, A. R. "Multi-Hundred Horsepower Permanent Magnet Brushless Disc Motors," in 
Proc. IEEE APEC Applied Power Electronics Conference, 1994, pp. 351-355.

[6] Pillay, P. and Krishnan, R. "Application Characteristics of Permanent Magnet Synchronous and Brushless DC Motors for Servo Drives," IEEE Trans. on Ind. Applicat., vol. 27, no.5, pp. 986-996, Sept/Oct. 1991.

[7] Low T. and Jabbar, M.A. "Permanent-Magnet Motors for Brushless Operation," IEEE Trans. on Ind. Applicat., vol. 26, no.1, pp. 124-129, Jan/Feb 1990.

[8] Krause, P.C. "Analysis of Electric Machinery," McGraw-Hill Company, 1987, pp.499-534.

[9] Yedamale, P. "Brushless DC (BLDC) Motor Fundamentals," Microship Technology Inc., 2003, pp.1-20.

[10] Ziegler, J. G., Nichols, N. B., "Optimum settings for automatic controllers," Trans. ASME, vol. 62, pp. 759-768, 1942.

[11] Astrom, K. J. and Hagglund, T., "PID controller," 2nd Edition, Instrument of Society of America, Research triangle park, North Carolina, 1995.

[12] Morari, M., and Zafiriou, E., "Robust process control," Prentice Hall, USA, 1989.

[13] Rivera, D. E., Morari, M., and Skogestad, S., "Internal model control - PID control design", Ind. Eng. Chem. Process Des. Dev., 25, pp. 252-265, 1986.

[14] Cohen, G. H. and Coon, G. A., "Theoretical considerations of retarded control," Trans. of ASME, vol. 75, pp. 827, 1953.

[15] Feng, Z., Wang, Q. G. and Lee, T. H., "On the design of multivariable PID controllers via LMI approach," Automatica, vol. 38, pp. 517-526, 2002.

[16] Ge, M., Chiu, M. and Wang, Q. G., "Robust PID controller design via LMI approach," J.Process Control, vol.12, pp. 3-13, 2002.

[17] Ali W.H, Zhang Y, Akujuobi C.M, Tolliver C.L and Shieh L.S, "DSP-Based PID controller design for the PMDC motor," I.J. Modeling and Simulation, Vol 26, No 2, pp143-150, 2006.

[18] Changliang Xia, PeiJian Guo, Tingna Shi, Mingehao Wang, "Speed control of brushless DC motor using genetic algorithm based fuzzy controller", 2004 International Conference on Intelligent Mechatronics and Automation, Chengdu, China, 26-31 Aug. 2004.

[19] Picardi C., Rogano N., "Parameter Identification of Induction Motor Based on Particle Swarm Optimization," International Symposium on Power Electronics, Electric Drives, Automation and Motion, May 23-26, 2006.

[20] Ehab H.E. Bayoumi, Hisham M. Soliman, "PID/PI tuning for minimal overshoot of permanent- magnet brushless DC motor drive using particle swarm optimization", Electromotion Scientific Journal, Vol. 14, No. 4, pp.: 198-208, 2007.

[21] Kennedy, J. and Eberhart, R.C. Swarm Intelligence, Morgan Kaufmann, San Francisco, 2001.

[22] Ehab H.E. Bayoumi, "Parameter estimation of cage induction motors using cooperative bacteria foraging optimization", Electromotion Scientific Journal Vol. 17, No. 4, pp: 247-260, 2010.

[23] El-Abd, M. and Kamel, M., "A taxonomy of cooperative search algorithms, "Proceedings of the 2nd International Workshop on Hybrid Metaheuristics, pp.32-41, 2005.

[24] R.Krishnan, "Permanent Magnet Synchronous and Brushless DC Motor Drives: Theory, Operation, Performance, Modelling, Simulation, Analysis and Design, Part 3: Permanent Magnet Brushless DC Machines and Their Control," Virginia Tech, Blacksburg, 2000.

[25] Shatnawi M. and Bayoumi, E "Brushless DC Motor Controller Optimization Using Simulated Annealing," in 2019 International Conference on Electrical Drives \& Power Electronics (EDPE), 2019.

[26] Kirkpatrick, S., Jr., D. G., Vecchi, M. P., 1983. Optimization by simulated annealing. Science 220 (4598), 671-680.

[27] Vega-Rodriguez, M. A., Gomez-Pulido, J. A., Alba, E., Vega-Perez, D., Priem-Mendes, S., Molina, G., 2007. Evaluation of different metaheuristics solving the rnd problem. In: Applications of Evolutionary Computing. Springer, pp. 101-110.

[28] Mendes, S. P., Molina, G., Vega-Rodriguez, M. A., Gomez-Pulido, J. A., Saez, Y., Miranda, G., Segura, C., Alba, E., Isasi, P., Leon, C., et al., 2009. Bench- marking a wide spectrum of metaheuristic techniques for the radio network design problem. Evolutionary Computation, IEEE Transactions on 13 (5), 1133-1150.

[29] Busetti, F., 2003. Simulated annealing overview.

[30] Henderson, D., Jacobson, S. H., Johnson, A. W., 2003. The theory and practice of simulated annealing. In: Handbook of metaheuristics. Springer, pp. 287-319.

[31] Geman, S., Geman, D., 1984. Stochastic relaxation, gibbs distributions, and the bayesian restoration of images. Pattern Analysis and Machine Intelligence, IEEE Transactions on (6), 721-741.

[32] Salamon, P., Sibani, P., Frost, R., 2002. Facts, conjectures, and improvements for simulated annealing. SIAM. 
[33] Ingber, L., 1993. Simulated annealing: Practice versus theory. Mathematical and computer modelling 18 (11), 29-57.

[34] Smith, K. I., Everson, R. M., Fieldsend, J. E., Murphy, C., Misra, R., 2008. Dominance-based multiobjective simulated annealing. Evolutionary Computation, IEEE Transactions on 12 (3), 323342.

[35] Ishikawa, M., Toya, T., Hoshida, M., Nitta, K., Ogiwara, A., Kanehisa, M., 1993. Multiple sequence alignment by parallel simulated annealing. Computer applications in the biosciences: CABIOS 9 (3), 267-273.

[36] Kim, J., Pramanik, S., Chung, M. J., 1994. Multiple sequence alignment using simulated annealing. Computer applications in the biosciences: CABIOS 10 (4), 419-426.

[37] Tomshine, J., Kaznessis, Y. N., 2006. Optimization of a stochastically simulated gene network model via simulated annealing. Biophysical journal 91 (9), 3196-3205.

[38] Kundu, S., Mahato, M., Mahanty, B., Acharyya, S., 2008. Comparative performance of simulated annealing and genetic algorithm in solving nurse scheduling problem. In: Proceedings of the International MultiConference of Engineers and Computer Scientists. Vol. 1.

[39] Bertsimas, D., Nohadani, O., 2010. Robust optimization with simulated annealing. Journal of Global Optimization 48 (2), 323-334.

[40] Huang, K.-Y., Hsieh, Y.-H., 2011. Very fast simulated annealing for pattern detection and seismic applications. In: Geoscience and Remote Sensing Symposium (IGARSS), 2011 IEEE International. IEEE, pp. 499-502.
[41] Bhaskara, R. M., de Brevern, A. G., Srinivasan, N., 2012. Understanding the role of domain-domain linkers in the spatial orientation of domains in multi- domain proteins. Journal of Biomolecular Structure and Dynamics, 1-14.

[42] Shatnawi, M. and Zaki, N. "Prediction of protein inter-domain linkers using compositional index and simulated annealing," in Proceedings of the 15 th annual conference companion on Genetic and evolutionary computation, 2013.

[43] Jaraiz-Simon, M. D., Gomez-Pulido, J. A., VegaRodriguez, M. A., Sanchez- Perez, J. M., 2013. Simulated annealing for real-time vertical-handoff in wireless networks. In: Advances in Computational Intelligence. Springer, pp. 198209.

[44] Shatnawi, M. and Zaki, N., "Inter-domain linker prediction using amino acid compositional index," Computational biology and chemistry, vol. 55, pp. 23--30, 2015.

[45] Tomshine, J., Kaznessis, Y. N., 2006. Optimization of a stochastically simulated gene network model via simulated annealing. Biophysical journal 91 (9), 3196-3205.

[46] Ishikawa, M., Toya, T., Hoshida, M., Nitta, K., Ogiwara, A., Kanehisa, M., 1993. Multiple sequence alignment by parallel simulated annealing. Computer applications in the biosciences: CABIOS 9 (3), 267-273.

[47] Kim, J., Pramanik, S., Chung, M. J., 1994. Multiple sequence alignment using simulated annealing. Computer applications in the biosciences: CABIOS 10 (4), 419-426.

[48] Kirkpatrick, S., Jr., D. G., Vecchi, M. P., 1983. Optimization by simulated annealing. Science 220 (4598), 671-680.

\section{Creative Commons Attribution License 4.0 (Attribution 4.0 International, CC BY 4.0)}

This article is published under the terms of the Creative Commons Attribution License 4.0

https://creativecommons.org/licenses/by/4.0/deed.en US 